\title{
Fotografias e legendas do jornal BRASILdeFATO: discurso e ideologia
}

\begin{abstract}
RESUMO
O presente trabalho visa rastrear a ideologia instalada em fotografias e legendas sobre a questão agrária publicadas no jornal BRASILdeFATO. Utiliza-se o referencial teórico da Análise do Discurso de matriz francesa, cujos pressupostos atentam para uma leitura menos ingênua do discurso textualizado na mídia, a qual toma o discurso não verbal como "imparcial", como prova incontestável de uma realidade objetiva que independe da formação social e ideológica do sujeito-fotojornalista.
\end{abstract}

\section{PALAVRAS-CHAVE}

análise do discurso

ideologia

fotojornalismo

\section{ABSTRACT \\ The present work seeks to trace the ideology installed in pictures and legends on the agrarian subject published in the newspaper BRASILdeFATO. It is used the theory of the French matrix of the Discourse Analisys, whose presuppositions look at a less naive reading of the discourse in the media, which takes the non verbal discourse as "impartial", as unanswerable proof of an objective reality that doesn't depend on the social and ideological formation of the subject-photo journalist.}

\section{KEY WORDS}

discourse analisys

ideology

picture journalism
Considerando que textos e imagens da mídia circulam como presença constante e repetitória na atualidade, este trabalho busca refletir, à luz da Análise do Discurso (AD) de filiação francesa, a respeito do efeito ideológico de evidência em um corpus constituído por fotografias e legendas do jornal BRASILdeFATO, lançado durante o Fórum Social Mundial em 2003. Como referência, utilizamos trabalhos que teorizam o discurso (Pêcheux, 1999 e Orlandi, 2006), a imagem fotográfica (Dubois, 1993 e Joly, 1996) e o não-verbal (Souza, 2001), buscando compreender como o corpus selecionado faz falar certos sentidos e não outros, inscrevendo recortes, angulações e modos de enquadramento e significação da realidade.

Também, faz-se mister investigar como o discurso das legendas se relaciona e se cruza com os sentidos do não-verbal, evidenciando marcas de heterogeneidade e estabilizando interpretações. Com deste trabalho, pretendemos estimular uma leitura menos ingênua das formulações jornalísticas, inscrevendo opacidade e questionamento no modo como a informação é vista na mídia, a saber, como dado neutro, objeto e fiel à realidade; pretendemos também rastrear as marcas de heterogeneidade no dizer midiático, discutindo como hoje se inscreve a confrontação, ao modo de uma arena discursiva, entre os jornais da chamada grande imprensa, que materializam o "discurso dominante" (Orlandi, 1996), e outras vozes de oposição, que desestabilizam e desalinham tal discurso, instalando resistências em publicações tidas como marginais.

Primeiramente traçaremos um breve perfil sobre o contexto sócio-histórico da mídia nos dias atuais, para compreender como o sentido dominante é sustentado pela imprensa majoritária com a qual o discurso do BRASILdeFATO rompe. Feito isso, desenvolveremos uma reflexão das imagens e legendas midiáticas à luz da teoria da $\mathrm{AD}$, quebrando alguns mitos referentes à suposta "literalidade" dos dizeres midiáticos e à pretensa objetividade das imagens fotográficas; finalmente, analisaremos três fotografias e legendas do BRASILdeFATO, colhidas nos anos de 2005 e 2006, indiciárias do modo como vozes silenciadas em outros veículos de comunicação aparecem manifestas nesse jornal.

\section{As ilusões do sujeito: objetividade, referencialidade e neutralidade}

A Análise do Discurso surge, em fins dos anos 60, apoiada no "tripé" de três campos teóricos, Lingüística, Marxismo e Psicanálise (Ferreira, 1998), como um modo de estimular análises menos formalistas, fundar o conceito de discurso e colocar em xeque o "conteudismo das

\author{
Lućilia M. S. Romã \& Jonathan R. B. da Silva \\ USP \\ tantpalavras@uol.com.br
}


análises (o que o autor quis dizer; o que este texto significa; qual a influência do contexto no sentido do texto, etc.), é contrária também ao excessivo formalismo das descrições que além de denegar a história, esteriliza a língua e apaga o sujeito" (Ferreira, 1998, p. 202). Considerando língua, história e sujeito, discurso é entendido como "efeito de sentido entre sujeitos historicamente determinados" (Pêcheux, 1997), ou seja, pensar o discurso significa considerar a posição ocupada pelo sujeito em uma dada conjuntura sócio-histórica, significa entender as palavras como heterogêneas, propensas a equívocos, furos e/ ou deslizamentos de sentidos. Também significa considerar que todos os enunciados são atravessados pelo político e constituídos por sujeitos interpelados pela ideologia, o que tem importância para nós, pois, no discurso jornalístico, o sujeito sustenta-se na ilusão de ser a fonte do que diz e de assegurar uma relação direta entre as palavras e o mundo.

A noção de sujeito do discurso, epicentro desta teoria, não considera o sujeito como um ser empírico, cartesiano, fonte de seu próprio dizer e das interpretações que faz dos dizeres alheios, mas posição-sujeito afetada por dois esquecimentos. O primeiro diz respeito ao modo como o sujeito supõe ser ele a origem de suas palavras e é condição necessária para que se possa enunciar.

O esquecimento número 1 é o que dá conta do fato de que o sujeito falante não pode, por definição, se encontrar no exterior da formação discursiva que o domina. Ou seja, o sujeito se constitui pelo esquecimento do que o determina. (...) Pelo esquecimento número 1 é que tem a ilusão de ser a origem do que $\operatorname{diz}$ (ORLANDI, 2006, p. 21).

O segundo esquecimento é de especial importância para apreender nossa oposição à suposta neutralidade da mídia. Refere-se ao modo como o sujeito escolhe determinados sentidos e significantes, esquecendo-se de que existem outros sentidos possíveis de dizer.

O esquecimento número 2 é da ordem da formulação. O sujeito esquece que há outros sentidos possíveis. Ao longo de seu dizer vão-se formando famílias parafrásticas de tudo aquilo que ele podia dizer, mas não disse. Esse esquecimento não é da ordem do inconsciente e muitas vezes o sujeito até recorre a essas margens de seu dizer para precisar o que está dizendo (ORLANDI, 2006, p. 21).

Os dois esquecimentos nos possibilitam entender o processo de produção de sentidos no discurso jornalístico, pois o sujeito-jornalista considera-se imparcial e isento como se as suas palavras surgissem no momento em que são ditas, representassem um relato "acima do bem e do mal" sem filiações a outros dizeres, a um ou outro posicionamento. Se levarmos em conta a pretensa objetividade da mídia, o esquecimento $\mathrm{n}^{\circ} 2$ é força-motriz para derrubar a crença do sujeito-jornalista de poder buscar, entre uma formulação ideológica e outra que o relato da notícia propicia, um meio-termo neutro no qual ele poderia enunciar na segurança de se fazer compreendido sem apoiar um dos lados, mas simplesmente apontando os fatos seguindo uma cartilha de significantes que, para esse sujeito, não carregam consigo ambigüidade e nem carga política, buscando fugir dos interdiscursos que caracterizam posições políticas, visando signos "objetivos" que, sonham os jornalistas, seriam entendidos de modo universal pelos leitores. Ora, se o discurso é inerentemente materializado de forma ideológica, seguindo padrões lingüísticos e sociais preexistentes aos quais o sujeito-jornalista deve se assujeitar, sob pena de não conseguir estabelecer um diálogo coerente com o(s) interlocutor(es), então não há como fugir de deslizamentos ideológicos.

\section{Interdiscurso e a naturalização dos sentidos nas legendas e fotografias}

Notamos, então, que os meios de comunicação de massa enunciam a partir de uma posição no contexto sóciohistórico no qual estão inseridos, recortando interdiscursos já ditos em outro lugar. Arbex Jr. (Arbex Jr 2001, p. 60) define que: "Se em sua fase inicial a imprensa cumpria o papel de informar, divulgar e intermediar publicamente o raciocínio de pessoas privadas, agora, ao contrário, o público passa a receber a informação determinada por grupos privados". A dependência dos anunciantes foi expandida sob a égide do imperialismo e do atrelamento da mídia com as novas tecnologias, como a Internet, para acompanhar o mercado e o ritmo de informações ininterruptas, que tanto caracteriza a nova era informacional.

Se o atual contexto, como averiguado, favorece a conexão entre mídia e investimento publicitário, não é de se estranhar que a imprensa de maior circulação age em conluio com o capital, servindo como tentáculo do mesmo ao naturalizar sentidos autorizados pelas engrenagens do mercado como "legítimos" (Payer, 2005). Formações discursivas contrárias são tidas como marginais e, com freqüência, silenciadas nas páginas dos barões da mídia, cujo despotismo por vezes é vinculado de modo direto a favorecimentos políticos. Quem já viu o clássico absoluto do cinema Cidadão Kane ${ }^{1}$ (Citizen Kane, 1941), filme de estréia do diretor Orson Welles, baseado na vida do magnata do jornalismo William Randolph Hearst (Charles Foster Kane no filme, interpretado pelo próprio Welles), sabe bem disso. E a versão tupiniquim de Hearst foi evidenciada na imagem do falecido Roberto Marinho, da Rede Globo, no documentário Muito Além do Cidadão Kane ${ }^{2}$, datado do início dos anos noventa. Para colocar em circulação a região de sentidos "autorizada" pelos anunciantes, a mídia inscreve um sentido dominante que se apresenta como forma única de enunciar (Romão, 2004, 2005), destinando as demais ao apagamento. O sujeito-leitor do jornal pode não perceber o 
silenciamento de certos sentidos, limitando-se à encarar os dizeres da imprensa como literais:

Não há um centro, que é o sentido literal, e suas margens, que são os outros efeitos de sentido. Só há margens. Por definição, todos os sentidos são possíveis e, em certas condições de produção, há a dominância de um deles. O sentido literal é um efeito discursivo. O que existe, é um sentido dominante que se institucionaliza como produto da história: o 'lite$\mathrm{ral}^{\prime}$. No processo que é a interlocução, entretanto, os sentidos se recolocam a cada momento, de forma múltipla e fragmentária (ORLANDI, 1996, p. 144).

O efeito discursivo da dominância acima referido, entretanto, pode, em dado momento, abrir margem para outras interpretações que rompem com a memória dos sentidos naturalizados, desregulando-os (Pêcheux, 1999), desestabilizando que parece evidente e sedimentado, inscrevendo instabilidade nas fissuras no discurso dominante. Isso é o que faz o discurso do jornal BRASILdeFATO, possibilitando a emergência de outras interpretações dos fatos, tão distintas daquelas propagadas pela grande mídia ancorada no capital publicitário. Como veremos a seguir, um observatório rico para a interpretação desse processo dá-se no âmbito da imagem e da legenda.

No imo do conceito ilusório de enunciado neutro da imprensa está a fotografia, que é o alicerce sustendador do mito da imparcialidade e que tende a ser compreendida como a prova cabal de uma realidade que, sonham os leitores incautos, não depende da formação ideológica e social do veículo que lhe traz o relato. Esse mito, contudo, é amplamente questionado pela Análise do Discurso e pelos teóricos da imagem. Joly (Joly, 1996), por exemplo, enfatiza que: "uma foto (...) revela a personalidade, as escolhas, a sensibilidade do fotógrafo que a assina" (Joly, 1996, p. 58). Desconstruir esse falso espelho do real evidenciado pela fotografia não é fácil, pois a imagem, em geral, é dotada de um inegável quê de realidade. "A foto é literalmente uma emanação do referente. De um corpo real que estava ali, são partes das radiações que vêm me tocar, eu que estou aqui; pouco importa a duração da transmissão; a foto do ser desaparecido vem me tocar como os raios atrasados de uma estrela." (Barthes, 1980 apud Dubois, 1993, p.60). E se entendermos a fotografia deste modo, haveremos de considerar que os raios não são a estrela em si, mas parte dela. Do mesmo modo, a foto é parte de uma seqüência de movimentos que, congelada em um instante, nos dá apenas a dimensão de um raio.

Portanto, a foto é um traço de realidade que, até certo ponto, de fato independe da "vontade" do sujeito-fotojornalista, que é interpelado em sujeito e recorta a seqüência de ações em um momento, dá o corte da cena em um ponto, marca um enquadramento. A fotografia, assim sendo, é de fato um atestado de existência do referente, mas não mais que isso, já que os significados que ela recebe são materializados como efeito de leituras de sujeitos. A construção de sentidos do não-verbal dá-se em torno de elementos como iluminação, cores, ângulos, corte, planos e enquadramento, que aparecem na mídia como realidade documentada sem "escolhas", realidade de fato, dado puro sem "filtros". Antes, convém ressaltar que essa qualidade de traço da realidade das imagens fotográficas são perfeitas armadilhas para fazer falar a sua suposta isenção:

Parece passar despercebido o fato de a fotografia jornalística procurar se colocar no ângulo possível a um observador comum, como se dissesse algo assim: 'Se estivesse lá, no lugar onde foi produzida esta imagem, você provavelmente veria esta cena do modo como a mostramos'. Embora se saiba que isso não é totalmente possível, pois o fotógrafo profissional (que muitas vezes faz dezenas ou centenas de fotos consecutivas de um determinado evento para selecionar aquela que lhe parece mais significativa) dispõe de diversos recursos e experiências que o olho humano comum (mesmo com equipamentos semelhantes aos do repórter fotográfico) não conseguiria reproduzir, exceto de maneira involuntária (ZANCHETTA JR, 2004, p. 84-85).

No meio jornalístico, as fotografias significam de modo intertextual, partindo do pressuposto que o leitor possui a "bagagem" necessária para conseguir realizar as interpretações de certas imagens, tanto nas áreas de política e economia quanto em esportes (Zanchetta Jr, 2004), dialogando com fotografias precedentes do próprio jornal ou de outros veículos. Esse gesto de inscrever sentidos sobre imagens só é possível para aqueles sujeitos que têm acesso à memória discursiva. Se a leitura dos enunciados verbais já está configurada para fundamentar sentidos "autorizados" pela classe dominante, a questão ganha peso quando se trata do discurso não-verbal, cuja ilusão de prova irrefutável da realidade dificulta os gestos interpretativos do leitor.

Mais importante que pensar os sentidos construídos em elementos mostrados na/ pela fotografia, é considerar que ela tem um incontestável poder de silenciar vozes através de um jogo metonímico que supõe dar pistas do todo pelas partes, condenando sentidos "inconvenientes" ao apagamento. Um exemplo é a forma como são retratadas as manifestações dos trabalhadores rurais sem-terra nos veículos inscritos na FD dominante em comparação com os jornais que se filiam aos sentidos considerados marginais, dentre eles destacamos a voz do o BRASILdeFATO: retrata-se uma parte das manifestações para representar o todo do evento. Tais partes são representadas pelas fotos "escolhidas" a dedo pelo sujeito-editor, dentre outras tantas que o sujeito-fotojornalista registrou. Sabe-se que os fotógrafos da mídia concebem registros fotográficos de um evento dezenas - senão 
centenas - de vezes, e a escolha de uma ou duas fotos que farão parte da publicação impressa (ou eletrônica) se dá de modo ideológico, silenciando os sentidos que circulariam caso as fotos descartadas fossem selecionadas. E embora a mídia de massa estabeleça um sentido dominante, os sentidos marginalizados podem eclodir em outros órgãos da imprensa ou mesmo dentro do próprio jornal em outros lugares, com, por exemplo, no cartum.

Esse cruzamento de vozes [aquele presente na mídia] é amarrado de maneira heterogênea, mas, ao mesmo tempo, tenta parecer um produto final e chegar ao leitor como efeito de unidade, neutralidade, exatidão e objetividade. Efeitos esses pretendidos e, não raro, vendidos como atributos diferenciais por certos órgãos da imprensa. (...) No caso do discurso jornalístico, vale destacar que, ao mesmo tempo em que um sentido dominante se impõe e uma linha editorial é firmada, outros sentidos podem irromper de modo imprevisível, colocando espaços de resistência, dizeres marginais, campos semânticos indesejáveis e não legitimados em cena (ROMÃO, 2005, p. 5)

O papel da legenda é crucial na condensação dos sentidos apontados como naturais, de modo que o leitor/consumidor do jornal tenha a certeza de que esses dizeres são óbvios, sem buscar atravessá-los em sua opacidade e sem interpretar o litígio que ela trava com a fotografia. O não-verbal, deste modo, fica subjugado ao verbal, "seja através do texto que acompanha a fotografia seja através de legendas que, mais diretamente, nos envolvem 'nessa única leitura possível'" (Soares, 2006, p. 178). Diálogos entre a legenda e a imagem, notadamente, se dão de modo heterogêneo nos discursos midiáticos, instalando efeitos ideológicos de evidência e inscrevendo uma discursividade de leitura para o fato e estabilizando um único modo de dizer.

\section{Quebrando o "espelho do real": a marca da ideologia em três recortes do BRASILdeFATO}

Abaixo seguem as análises de três fotografias e suas respectivas legendas publicadas no jornal BRASILdeFATO entre maio de 2005 e maio de 2006. Buscamos, nesse discurso midiático, como se materializa o sentido de prova íntegra e de registro objetivo da realidade em fotografias e legendas.

O registro fotográfico acima, datado de maio de 2005, foi assinado por Francisco Roja, apresenta a imagem de um grupo de manifestantes do MST (identificados pela vestimenta e pela bandeira à esquerda), sustentando uma placa, vista no centro da foto, com os dizeres "Fazenda do FMI Banqueiros Agronegócio"; e ainda um cartaz, centralizado na parte de baixo da fotografia, anunciando: "Marcha Nacional pela Reforma Agrária". A legenda que vem abaixo enuncia: "Governo se com-

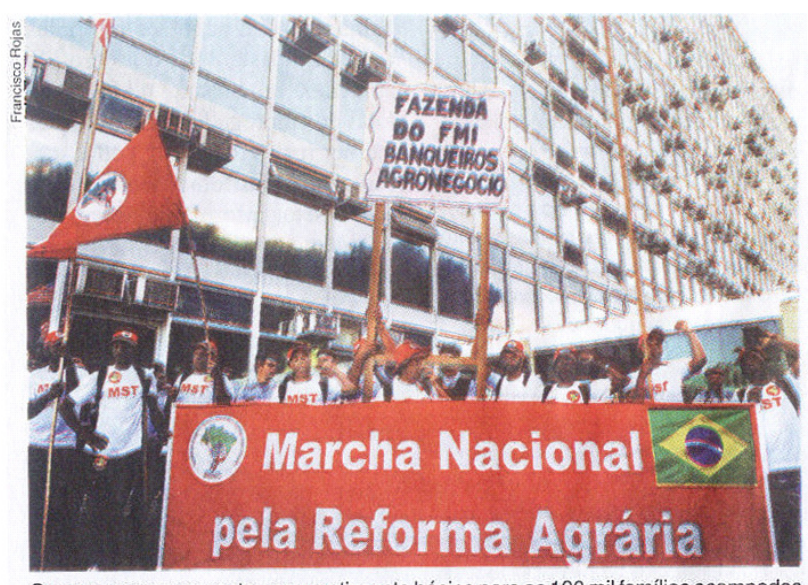

Governo se comprometeu a garantir cesta básica para as 120 mil famílias acampadas

prometeu a garantir cesta básica para as 120 mil famílias acampadas". Elemento fundamental da significação dessa imagem é o prédio ao fundo, que parece fixar o dado do contexto sócio-histórico, qual seja, o local em que os manifestantes realizam a marcha. Com muitos andares, o plano do prédio forma a maior parte da fotografia, erguendo-se onipotente no plano de fundo. De modo tímido, o céu azulado ganha espaço somente no canto superior direito. O branco da parede, as linhas geometricamente calculadas das janelas e o azul-claro do céu (cor fria, lembremos) refletido nos vidros instalam um tom de assepsia, sem irregularidades, sem lugar para o diferente, ou para as linhas curvas, tortas, dissonantes. Em nenhuma das janelas pode se ter uma idéia sequer vaga do que há no interior do prédio, aqui remetendo a uma construção pública, sem rosto, "encapsulada" numa realidade só dela, enquanto fora do edifício os trabalhadores, representados pelos manifestantes em carne e osso, movimentam-se com suas palavras nos bonés, no cartaz e, sobretudo na faixa no centro da imagem. Os trabalhadores, como nas janelas do prédio, também possuem regularidades, embora conceituem uma fila em movimento, desregulada por gestos diferentes. Repetem-se os bonés, camisas (com as letras do MST) e calças - mas ao contrário das janelas do prédio, "racionalmente" organizadas e os manifestantes têm intersecção justamente em seu dizer, como indicador de movimento e a posição corporal é diversificada num louvor às diferenças, embora com ideais em comum.

Observando a escolha dos planos e o ângulo, observamos que o sujeito-fotojornalista registrou a cena da altura dos trabalhadores, mostrando-os como semelhantes ao sujeito-fotógrafo (e, mais tarde quando o registro for publicado, ao sujeito-leitor), enquanto o prédio, distanciado, ganha aspecto cada vez mais longínquo conforme o nível dos andares aumenta. Nessa perspectiva, o discurso assume efeitos de denúncia do cartaz sobre o Fundo Monetário Internacional, os banqueiros e o agronegócio. Içado pelos trabalhadores ao chão, que, de forma simbólica, fazem falar o modo como a classe operária sustentou a elite, inscrito histórico dos sentidos sobre 
desigualdade no país. A placa é erguida de modo que fique distante das pessoas no chão, e o branco que a caracteriza associe-se com o prédio no fundo. Mais embaixo, na altura dos manifestantes, o cartaz vermelho que nomeia a marcha pela reforma agrária, bem maior que a placa sobre o FMI. Os dois cartazes inscrevem uma representação da "pirâmide do capitalismo", em que uma pequena minoria, metaforicamente desenhada pelo tamanho da plaquinha sobre o FMI, é (literalmente) sustentada pelos ombros e braços dos trabalhadores, que anseiam por reforma agrária e igualdade de renda e acesso aos meios de produção. O alinhamento dos dois cartazes, com o menor centralizado acima da faixa vermelha instala/marca esse efeito de sentidos. Há ainda a associação ao estrangeiro na placa menor, através da menção ao FMI, do que "é nosso" e do que "é de fora", e da valorização dos brasileiros no cartaz vermelho, pelo uso do significante nacional, confronte de duas FDs, quais sejam, a que olha do Brasil de fora e que o considera no seu interior, especialmente ancorada no trabalho.

$\mathrm{Na}$ legenda, há reforço para a idéia de luta de classes já evidenciada na fotografia. O governo aqui é visto como instituição que deve algo aos trabalhadores, quase subvertendo a hierarquia do trabalhador submetido ao Estado, o qual deve prestar contas à classe dominada e não o contrário (essa postura, por sinal, é denominador comum nas legendas do BRASILdeFATO). Cita-se a cesta básica como material que o governo deve oferecer, ou seja, remete-se diretamente à noção do acesso aos meios de produção, capazes de garantir o acesso ao alimento, tão caros ao MST. O uso do numeral 120 mil, em algarismos, engrandece a missão dos manifestantes ao colocá-los em grande número, o que marca um modo de o sujeito fazer falar a quantidade de pessoas necessitadas de alimentação.

Neste registro de Paulo César Lima, oriundo de uma publicação de setembro de 2005 do BRASILdeFA-

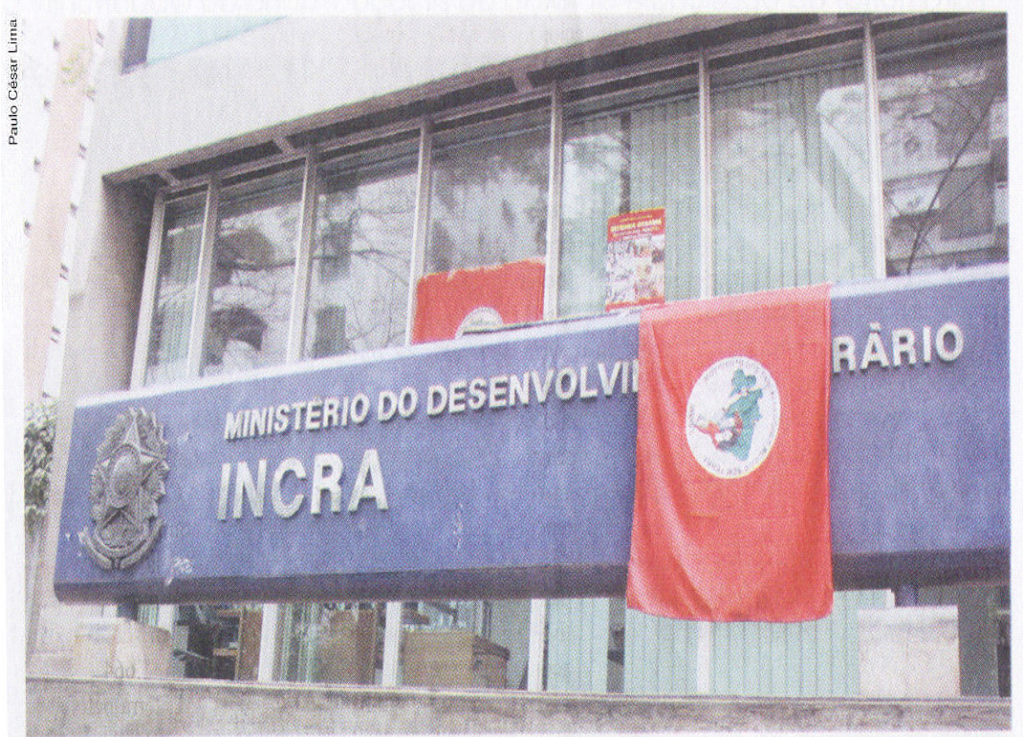

Trabalhadores sem-terra ocupam sede do Incra em São Paulo e outras capitais, para cobrar do governo a reforma agrária ria". Pela ausência de pessoas nessa fotografia o sujeitofotojornalista marcou o confronto no âmbito de um prédio e de uma bandeira, ou seja, no corpo da cidade e no lugar em que os sentidos do urbano dão sustentação ao equívoco no campo. Ao mostrar um embate Incra versus MST através de bandeiras e letreiros, a imagem vai bastante além do caráter indiciário e lida diretamente com o simbólico/ideológico.

O teor fortemente simbólico da fotografia de Paulo César Lima reclama essa leitura para além do referente por si só, pois salta aos olhos a ideologia presente na sobreposição da bandeira dos sem-terra cobrindo a fachada do Incra. Por cobrir a área correspondente aos dizeres "Ministério do Desenvolvimento Agrário", o efeito ideológico notadamente escapa do plano meramente indiciário para representar a luta de vozes entre governo e trabalhadores rurais. Mais que isso: a bandeira cobre exatamente os significantes "desenvolvimento agrário", deixando o "Ministério" totalmente à mostra. A sigla do Incra também fica totalmente exposta. O sentido aí instalado remete à possibilidade de descaso do governo para com a causa do MST, afinal, o Ministério e o Incra existem, aparecem, são evidenciados. Já o desenvolvimento agrário (que deveria ser o escopo dessas instituições) não acontece, exceto parcialmente, daí não é totalmente exposto na imagem. Nota-se ainda que as venezianas atrás da área onde se encontra a bandeira estão fechadas, enquanto as demais estão abertas, mostrando o interior do prédio através da transparência dos vidros - e justamente na área que corresponde às palavras Ministério e Incra, reiterando a tese dessa instituição como mera "fachada" sem causar desenvolvimento agrário na prática, pois à direita do prédio, quando as janelas dialogam com o símbolo do MST e o desenvolvimento agrário, os "olhos de vidro" do estabelecimento, as janelas, estão TO, optou-se por evidenciar a fachada do prédio do Incra, com a sigla no letreiro ocupando a quase totalidade da imagem. Uma bandeira do MST, à direita, cobre parte do letreiro, na parte correspondente as palavras "desenvolvimento agrário". Desta vez, não há cartazes nem pessoas registradas. A legenda inscreve: "Trabalhadores sem-terra ocupam sede do Incra em São Paulo e outras capitais, para cobrar do governo a reforma agrá- recolhidas. Na ausência de pessoas dá-se num embate entre instituição oficial e movimento social, aqui assinalados para além dos líderes e figuras do governo, mas indiciada por um órgão do governo e por um movimento social do campo, especificamente. No enunciado da legenda, o célebre significante "ocupam" (conflituoso com o invadem que seria redigido na imprensa de outra filiação ideológica - antagonismo que Oliveira, 2002, cita em 
sua tese) dá as caras ancorando a discursividade do MST e o evento do assentamento no Incra paulistano. Além disso, a subversão hierárquica naturalizada do Estado como "dono" dos trabalhadores marca aqui o uso do verbo cobrar, com o qual reivindicam uma exigência de algo que é direito dos trabalhadores. Tal verbo, ressaltamos, surge como uma regularidade no interdiscurso do BRASILdeFATO, pois foi verificado também em outras análises (apontadas em Romão e Silva, 2007). O verbo instala uma idéia de quase-coerção, colocando o governo como subordinado aos trabalhadores, forçando-o a significá-los, lembrando do direito à reforma agrária que ainda não foi atendido.

Nesta fotografia de maio de 2006, creditada à Joana Tavares, uma fila de aproximadamente quinze pessoas exibe seis cartazes (além de outros parcialmente enquadrados) com os seguintes enunciados, da esquerda para a direita: "latifúndio", "agrotóxico", "multinacionais", "poluição", "agronegócio" e "poucas vagas", este último num cartaz dobrado e prejudicado pelo ângulo. A formulação da legenda é: “Este ano, romaria dos trabalhadores defendeu a união do movimento estudantil com diversos setores organizados da sociedade".

Na escolha do enquadramento dos cartazes, a fotojornalista (ou o editor do jornal) se encontrou num dilema parecido com o do analista documentário ao conceber palavras-chaves para indexar informações: tentou permitir que o máximo de dizeres possíveis dentro de um determinado espaço fosse visível ao leitor da imagem, mas teve que silenciar outros cartazes que nós leitores, de modo irreversível, jamais conheceremos. Caso a fotógrafa se afastasse mais no intuito de englobar mais palavras, ou supondo que isso foi feito e o editor quisesse incluir a imagem integral no jornal, a fotografia correria sério risco de ser prejudicada sob os olhos do leitor pelo excesso de informações, tendo em vista os limites de espaço inerentes à publicação impressa (talvez em formato online este empecilho pudesse ser solucionado).

As palavras que aparecem com mais nitidez e destaque no ângulo escolhido são "latifúndio", "agrotóxico" e "multinacionais", justamente os assuntos mais em voga no contexto recente em que o click foi dado (maio/ 2006). Uma espécie de "eixo sintagmático" incutido pela imagem por via desses significantes busca agregar todas as palavras ali materializadas, que evocam a memória para serem significadas. Se na imagem surgem antagonistas comuns às FDs dos movimentos sociais de esquerda como "latifúndio" e "poluição", elementos relativamente mais novos (deixados em destaque, como vimos) mereceram, segundo a composição da fila dos manifestantes ratificada pela ideologia do enquadramento fotográfico, figurar lado a lado desses "velhos inimigos". Quanto à legenda, o termo proeminente é "romaria", possivelmente retomado dado a constante significação de teor religioso que a imagem do MST e movimentos semelhantes recebem na mídia em geral há décadas, como a cruz vinculada ao MST (memória esta bastante citada em Oliveira, 2002). Remete-se à idéia do martírio cristão dos trabalhadores para realçar a missão da passeata. O restante da legenda discursivisa o efeito de otimismo ao celebrar a união do movimento estudantil com diversos setores organizados da sociedade. Que setores organizados seriam estes é informação omitida na legenda, mas o editor do jornal enfoca o dado com entusiasmo no ressalte do conceito de quantidade, através do significante diversos.

Trata ainda tais setores como organizados, palavra também muito usada em outras formações ideológicas que circulam na mídia majoritária, cuja significação geralmente traz consigo a idéia de "disciplina". Aqui talvez tenha a mesma função, mas servindo de alicerce para outra região de sentidos, aderindo ao caráter otimista geral da legenda ao indicar que os setores sociais que se uniram ao movimento estudantil estão "em ordem" ou "preparados", enaltecendo-os e encorajando-os. Senão, basta reparar como se retirarmos o significante organizados da legenda o sentido geral da mensagem não é alterado, mas perde considerável impacto na defesa à união dos movimentos ali noticiada.

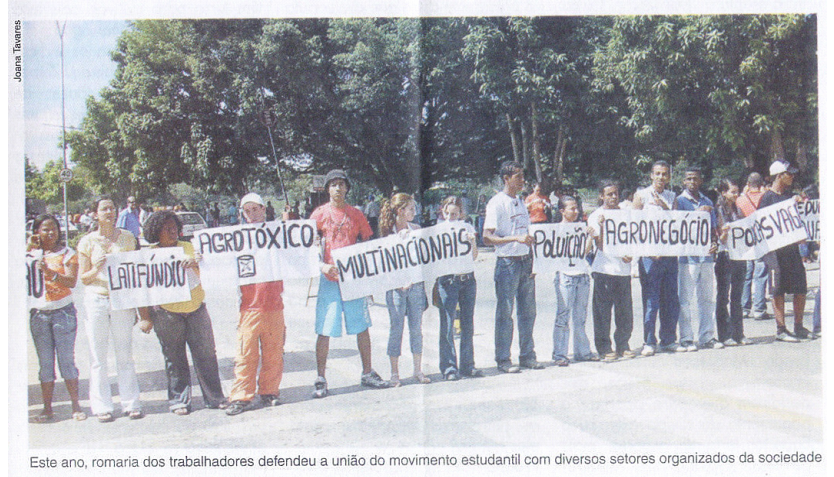

\section{Considerações finais}

Notamos que a legenda, ao inscrever sentidos sobre o não-verbal, aponta na direção de fixar e estabilizar os sentidos sobre ele e, no nosso caso, identificamos regularidades nos três recortes aqui analisados, quais sejam, a interpelação ideológica, a escolha por não silenciar os dizeres dos cartazes, forte uso do simbólico etc. O mito de "ver para crer" que o senso comum atribui à fotografia desde o século XIX tem no discurso jornalístico um produto de sistematização de certos dizeres. Todavia, é perceptível também que o BRASILdeFATO, numa postura audaciosa que rompe com a cartilha da imprensa majoritária autoproclamada "imparcial", materializa menos constrangimento ao levar os efeitos de sentido de reivindicação à tona, evidenciando o caráter de engajamento na luta social dos menos favorecidos (muito embora - não sejamos ingênuos - todo jornal usa da ilusória objetividade fotográfica para atingir o subconsciente dos leitores). Mas ainda que alguns veículos de comunicação mantenham postura menos alienante, o sujeito- 
leitor só pode interpretar os gestos de leitura do ideológico na fotografias e legendas, se tiver meios para rastrear esses traços de heterogeneidade no discurso midiático. E é isso que a Análise do Discurso propicia ao sugerir leituras menos inertes, que levem em conta o sócio-histórico-ideológico, marcar o gesto de ler e desnaturalizá-lo afAMECOS

\section{NOTAS}

1. Disponível em DVD pela Warner.

2. Título original: Beyond Citizen Kane. Disponível para download em alguns sites e softwares $p 2 p$ na Internet

3. Jornal BRASILdeFATO, edição do n 117 (26/05/ 05, p. 05)

4. Jornal BRASILdeFATO, edição do nº 135 (29/09/ 05, p. 03)

5. Jornal BRASILdeFATO, edição do n 166 (04/05/ 06, p. 05)

\section{REFERÊNCIAS}

ARBEX JR., J. Showrnalismo: a notícia como espetáculo. São Paulo: Casa Amarela pp.57-62, 2001.

BARTHES, R. La chambre claire. Note sur la photographie. Co-edição "Cahiers duCinema". Paris: Gallimard-Seuil, 1980.

DUBOIS, P. O ato fotográfico e outros ensaios. Campinas: Papirus, 1993.

FERREIRA, M. C. L. Nas trilhas do discurso: a propósito de leitura, sentido einterpretação. In: ORLANDI, E. P. (org.). A leitura e os leitores.. Campinas: Pontes, pp.201-208, 1998.

JOLY, M. Introdução à análise de imagem. Campinas: Papirus Coleção Ofício de Artee Forma, 1996.

OLIVEIRA, C. J. de. Terra e Jornalismo: o MST nas páginas da imprensa. São Paulo:Escola de Comunicação e Artes da Universidade de São Paulo (Tese de Mestrado),2002.

PAYER, M. O. Linguagem e sociedade contemporânea sujeito, mídia, mercado. RuaRevista do Núcleo de Desenvolvimento da Criatividade da Unicamp - Nudecri, n.11, 2005.

ORLANDI, E. P. Análise do Discurso. In: ORLANDI, E. P. (org.). Discurso eTextualidade. Campinas: Pontes, 2006.
O sentido dominante: a literalidade como produto da história. In: A linguagem eseu funcionamento: as formas do discurso. Campinas: Pontes, 1996.

PÊCHEUX, M. Papel da memória. Campinas: Pontes, 1999.

Semântica e discurso: uma crítica à afirmação do óbvio. Campinas: Editora da UNICAMP, 1997.

ROMÃO, L. M. S. Mais de perto, mil faces secretas sob a face neutra: consideraçõessobre a heterogeneidade no discurso jornalístico. Revista Signótica, Programa de PósGraduação em Letras e Lingüística - Faculdade de Letras, UFGO, vol. 17, n.2, 233 a 250p., 2005.

_. No (abril) vermelho: sentidos de resistência e silenciamento. Revista Graphos, Revista de Pós-Graduação em Letras, UFPB, vol 6, nº 2/1. 9 a 16p., 2004.

ROMÃO, L. M. S. e SILVA, J. R. B. O discurso inscrito nas legendas do JornalBRASILdeFATO. In: ROMÃO, L. M.S. EGASPAR, N. Discurso e texto: amultiplicidade de sentidos na Ciência da Informação. EDUSFCar, 2007 (no prelo).

SOARES, A. S. F. A Homossexualidade e a AIDS no Imaginário de Revistas Semanais (1985-1990). Niterói: Universidade Federal Fluminense (Tese de Doutorado), 2006.

SOUZA, T. C. C. A análise do não verbal e os usos da imagem nos meios de comunicação. Revista Ciberlegenda, n.6, 2001. Disponível em: <www.uff.br / mestcii/tania3>. Acesso em: 06 jun. 2007.

ZANCHETTA J. R., J. Imprensa escrita e telejornal. São Paulo: UNESP, 134 p., 2004. 